\title{
The Impact of Staging Conditions on Residential Real Estate Demand
}

\author{
Mark A. Lane, Michael J. Seiler, and Vicky L. Seiler
}

\section{Abstract}

This study is the first to examine the widely debated merits of staging a home for sale. We find that both homeowners and real estate agents believe staging conditions (furnishings and wall color) will significantly impact homeowners' willingness to pay for a property. Our results show that homeowners rationally do not significantly differ in their valuations based on staging conditions. However, staging conditions do influence the process, as we find a neutral wall color and good furnishings do significantly influence a buyer's perceived livability and overall opinion of the home. While these are a necessary condition for purchase, staging is not enough to result in a higher selling price.

Staging a residence for sale describes the process where a seller uses furnishings and decorations arranged in the most universally appealing way in the hopes of attracting the greatest number of potential buyers and thus receiving the highest possible offer price for the home. ${ }^{1}$ While no study has ever quantified the potential benefits of staging, the industry is large with many participants. Moreover, many stagers make undocumented claims such as, "Staging is no longer an option to many homeowners. It is often necessary to sell. The investment in staging is far less than a price reduction on the sales price of your home, or the additional cost of keeping your house on the market." 2 These claims have sparked a great debate among real estate agents across the country as to whether or not paying to have a home staged results in a marginally higher sale price sufficient to cover the cost of staging the home.

Rigorous quantitative studies of the effect of staging simply do not exist because of data constraints. As explained in Turnbull and Zahirovic-Herbert (2011), studies that examine related research questions, such as the time on the market (TOM) - sale price relation, sometimes include a control variable termed "vacancy" (e.g., Turnbull, Sirmans, and Benjamin, 1990; Asabere and Huffman, 1993; Sirmans, Turnbull, and Dombrow, 1995; Forgey, Rutherford, and Springer, 1996; Springer, 1996; Knight, 2002). But, vacancy and staging are not the same variable. In the rare instance where a Multiple Listing Service (MLS) dataset contains a variable that addresses vacancy, it is unclear how this variable is defined. ${ }^{3}$ One possible definition is that vacancy means that no one is residing in the home. This is procedurally important to real estate agents who bring clients to the residence because if someone occupies the space, professional etiquette holds that an appointment should be made before bringing by potential buyers. ${ }^{4}$ Turnbull and Zahirovic-Herbert (2011) use this definition of vacancy and argue that a vacated residence signals a more motivated seller (due to carrying costs) with less bargaining power. ${ }^{5}$ 
An alternative definition of vacant could mean that the home is physically empty. While this also implies no one is living in the home, it does not address whether or not the home is staged. If a home is furnished, it is unclear to the potential buyer if the home is occupied or not. If a home is staged and the owner does not occupy the residence, the seller's bargaining position should weaken (due to uncovered carrying costs), but if the staged home is occupied, (covered) carrying costs would not weaken a seller's bargaining position. In this sense, studies such as Turnbull and Zahirovic-Herbert (2011) are, at best, only examining a sub-set of vacant homes on the market where the vacated homes are not being staged. At worst, their "vacant" variable contaminates the difference between vacancy and staging because the researchers do not know the true status of the property. As a result, Turnbull and Zahirovic-Herbert (2011) cannot truly isolate the effect of vacancy because staging may or may not be present in their dataset.

Staging involves more than the mere inclusion and placement of furnishings and decorations. Real estate agents often advise sellers to paint their walls a neutral color that will appeal to the greatest number of potential buyers. To our knowledge, no available datasets report the color of the interior walls of a home. Recognizing that the effect of vacancy and staging cannot be disentangled using transactions data, we take an entirely different approach. Using a between subjects experimental design, we create six unique variants of a virtual home tour (good furnishings and a neutral wall color; no furnishings and a neutral wall color; poor furnishings and a neutral wall color; good furnishings and an unattractive wall color; no furnishings and an unattractive wall color; poor furnishings and an unattractive wall color), that truly holds everything else constant between each tour. We find that homeowners are willing to pay the (statistically non-significant) same price for the home under all six different treatments. Yet, in a follow-up examination, homeowners significantly believe that other homeowners would be willing to pay a greater price for a well-staged home and a significantly lower price for a home with an unattractive paint color in the main living area. This discrepancy between stated and revealed preferences is consistent with our robustness sample of real estate agents who erroneously also believe homeowners have a differential willingness to pay, depending on staging conditions.

Beyond a willingness to pay, we also examined the potential buyer's overall impression of the home and the home's livability. Interestingly, properly staged homes with neutral wall colorings do significantly add to these two home metrics. However, neither translates into a greater revealed willingness to pay for the home. As a result, while staging efforts do appear to impact potential buyers, the effect does not carry through all the way to the bottom line for sellers. We are quick to point out that there are two primary components relevant to the seller of a home. A seller's goal is to dispose of the property at the highest price and in the shortest time possible. While we clearly demonstrate that revealed willingness to pay prices are not impacted by staging conditions, our experimental design does not allow us to examine the TOM component of the equation. ${ }^{6}$

In sum, this study offers a contribution to the literature on several fronts. We use (1) an experimental design and (2) a national sample to (3) properly isolate and examine the, never before studied, effects of staging, and find the reason for the great debate surrounding the benefits of staging stems from a statistically significant discrepancy between people's stated preferences and their revealed preferences. Alternatively stated, 
people believe they would pay less for a home in a poor staging condition, but the reality is that they would not. Since homeowners do not get to keep the staging furniture, this revealed preference reflects rational behavior by potential buyers. This is not to say that buyers are fully rational, but rather that they are rational in this one component of the decision-making process. (4) This discrepancy between perceptions and reality is also shared by real estate agents, whose job it is (among many) to properly advise clients on the importance of staging conditions on the ultimate selling price of their home.

\section{Understanding Staging Conditions}

As previously discussed, both vacant and occupied homes can be staged or unstaged. Moreover, vacancy can be correlated with a number of additional extraneous variables that would contaminate the examination of staging such as foreclosures/short sales, new homes versus resales, controls for property condition (vacant homes are more likely to be dilapidated or otherwise unkempt), and so forth. As such, researchers should not use vacancy and staging terms interchangeably. Instead, we begin by giving proper definitions to all variables used in a study specifically designed to isolate the impacts of staging conditions on a buyer's overall impression of the home, the home's livability rating, and ultimately the buyer's revealed willingness to pay.

\section{Furnished Homes}

Turnbull and Zahirovic-Herbert (2011) argue that an empty home does not show as well as a (properly staged) furnished home because empty homes lack aesthetic and emotional appeal. Staging companies argue that a welcoming home allows potential buyers to more easily envision themselves living in the home, which is the first step (a necessary condition) towards buying the property. Alternatively, some agents argue that an empty home appears larger in size than a furnished home giving potential buyers the illusion that they are getting more for their money. These opposing arguments suggest the benefits accruing from a rigorous examination of the issue. Accordingly, we show a third of our sample a nicely furnished home, another third a poorly furnished home, and the final third an empty home. ${ }^{7}$

\section{Wall Color}

Real estate agents often advise sellers to paint the walls in their home a neutral color to appeal to the greatest number of potential buyers. This is especially true in the main living areas of the home. For example, if a third bedroom is painted pink, it would be unappealing for a family with only boys, but could well appeal to a family with at least one daughter. However, even a family with all daughters would likely find pink walls in the main living area of the home unappealing. Therefore, our design calls for half of our sample to view the home with an unattractive purple color on the walls whereas the other half sees a neutral tan color. ${ }^{8}$

\section{Transitory Effects of Staging Conditions}

Buyers understand that when they buy the home, they do not get to keep the furniture inside. ${ }^{9}$ Therefore, furnishings should have no impact on price. Wall coloring will be an 
attribute that gets passed through to the buyer upon sale, but paint is very inexpensive, relative to the cost of a home. For this reason, while there may reasonably be a rationally negative pricing response to wall color, the resulting price difference should still be relatively small.

\section{Variables used in the Analysis}

An abridged version of the data collection instrument used in this study is shown in the Appendix. Here, we define the main variables used throughout the analysis. Since we are interested in examining the effects of staging as well as the effects of interior wall coloring, we construct six $(3 \times 2)$ experimental treatments. To examine the effect of staging, we created three types of staging: (1) well-staged with nice furniture and furnishings; (2) poorly-staged with "ugly" furniture and furnishings; and (3) not-staged with no furniture or furnishings. To examine the effect of color, we created two types of color staging: (1) neutral colored with neutral wall colors throughout the main living area; and (2) "ugly" colored with offensively brightly colored walls throughout the main living area.

\section{A. Overall Assessment Measures}

Market Value Opinion

Overall Home Rating

Livability Rating

The participant's perceived value of the home. Participant's overall rating of the home on a scale from 1 (not at all favorable) to 9 (extremely favorable).

Participant's rating of their desire to live in the home on a scale from 1 (not at all favorable) to 9 (extremely favorable).

\section{B. Staging Condition Stated Value Variables}

Well Furnished Value

Poorly Furnished Value

Stated Paint Value 1

Stated Paint Value 2

\section{Demographic Variables}

Female Dummy

Children Dummy

Married Dummy

Caucasian Dummy
The participant's stated amount added to the property value from the property being well furnished.

The participant's stated amount subtracted from the value from the property being poorly furnished.

The amount the participants who saw the ugly paint said that they deducted from their estimate of the home's value.

The amount the participants who saw the neutral paint said they would have deducted from their estimate of the home's value.

The participant's gender. $(0=$ male; $1=$ female $)$ Does the participant have children? $(0=$ no; $1=$ yes)

If the participant is married. $(0=$ no; $1=$ yes $)$

Ethnicity of the participant. $(0=$ other; $1=$ Caucasian) 


\section{Exhibit 1. Links to 3-D Video Home Tours used in the Study}

\begin{tabular}{ll} 
Treatment & YouTube Link \\
\hline Neutral Walls; Good Furniture & http://youtu.be/EMVpA3Z6Yvl \\
Neutral Walls; Ugly Furniture & http://youtu.be/yEtWI-GJBeA \\
Neutral Walls; No Furniture & http://youtu.be/Mpk92SHR0FY \\
Colored Walls; Good Furniture & http://youtu.be/ODEDasJIFuE \\
Colored Walls; Ugly Furniture & http://youtu.be/DuGFFfLwiCU \\
Colored Walls; No Furniture & http://youtu.be/1JT7laB79bE \\
\hline
\end{tabular}

Notes: This table provides YouTube links to all the video treatments used in the study. Homeowners were randomly assigned to only one of the treatments and were then asked to answer the questions found in the Appendix.

Homeowner Experience Dummy

Income

Net Worth
Number of homes owned by the participant. $(0=$ none; $1 \geq 0$ )

Ranges from $1=$ Under $\$ 20,000$; to $7=$ Over $\$ 120,000$

Ranges from $1=$ Less than $-\$ 400,000$; to $9=$ Over $\$ 1,000,000$

\section{Experimental Design}

While most studies examine regional datasets stemming from granted access to localized data, our experimental design allows us to conduct a national study, which lends itself to more generalizable results. An experimental design has a further benefit of being able to control for exogenous, potentially contaminating variables. The potential drawback is that what is found under controlled conditions may not hold in the real world. Alternatively stated, transactions data are naturally confounded by a myriad of uncontrollable outside influences, whereas an experimental design is free from such biases, but is subject to scrutiny in terms of its ability to accept willingness to pay data as being equivalent to sales price data. For these reasons, we recognize that both transactions data and experimental data have their place in academic research. One should be used over the other only when it makes sense to do so. We argue that because staging conditions are not recorded in any existing transaction-based dataset, the use of an experimental design is not a matter of preference or superiority; it is a matter of necessity. Without using an experimental design, a study of the effects of staging conditions on residential real estate demand is simply not possible.

For these reasons, we perform a ceteris paribus analysis by creating a virtual home tour where we change only one attribute of the staging conditions at a time. This effort is made possible through a 3-D virtual home tour using professional-grade rendering software created by a local architectural firm. Exhibit 1 provides links to the full videos shown in each treatment. Without participants knowing that other treatments exist (a between subjects design), we then randomly selected a particular treatment and had 
homebuyers from across the country take the virtual home tour and answer the questions found in the Appendix.

\section{Data}

We utilize an existing network of homeowners from across the country who have previously identified themselves as being willing to participate in real estate research. In terms of participant integrity, the authors have launched several studies utilizing this data source and have continually developed techniques to ensure the data is as clean as possible (e.g., Seiler, Seiler, Lane, and Harrison, 2012; Seiler, 2014; Seiler, Lane, and Harrison, 2014). For example, we place hidden timers on all pages of the experiment. Since the videos run for 3 minutes and 40 seconds, we know that any participant who continues to the next section in less than this time has not watched the entire video. And for those who have cleared this threshold, we subsequently ask them to accurately communicate a verbally spoken code that was said during the video. This ensures the participant had his speakers on, which is necessary to hear the real estate agent who provides an audio description of the property during the tour. Participants who do not pass these hurdles are jettisoned from the analysis.

We further include two questions, spaced throughout the instrument, that simply ask the respondent to select a specific number to ensure they are reading each question carefully. If both of these questions are not answered correctly, the participant is excluded from the final sample and banned from all subsequent studies. Additionally, each person in the network is assigned an anonymous, but consistent and unique, identification number. In cases where the person has participated in a study from us in the past, we crosscheck their demographic answers to ensure consistency over time and remove those whose answers reveal unexplainable irregularities. ${ }^{10}$ Because the experiment is completed electronically, we know the exact starting and ending times, and therefore, how long the respondent took to complete the experiment. Average completion time is just over 10 minutes. $^{11}$

After screening the data for inclusion, 820 usable responses remain. In comparing the demographics of our collected sample to those of the national database of homeowners, we find that our primary sample is somewhat younger and contains a higher percentage of single people. Otherwise, the demographic profiles between the two groups are quite comparable in terms of ethnic make-up, income, and gender. Specifically, our sample relative to national homeowners found in the American Housing Survey and American Community Survey consists of White (80.2\%; 81.0\%), Black (5.9\%; 8.0\%), Hispanic (3.3\%; $3.1 \%)$, and Asian (7.1\%; 7.9\%), respectively. The average income in the sample falls in the $\$ 40,000$ to $\$ 60,000$ category, whereas the national average homeowner income is $\$ 60,000$. Where the samples differ are in terms of age (32.2 vs. 52), number of children under 18 years of age (33.3\% vs. 66.2\%), and percentage that are married $(35.9 \%$ vs. $52.3 \%$ ) for our sample versus the national sample, respectively.

\section{Robustness Sample of Real Estate Agents}

As a robustness check, we collect perceptions data from a group of real estate agents in the Hampton Roads, Virginia MSA. ${ }^{12}$ This group of agents was presented with our six 


\section{Exhibit 2. Descriptive Statistics for the Homebuyer Sample}

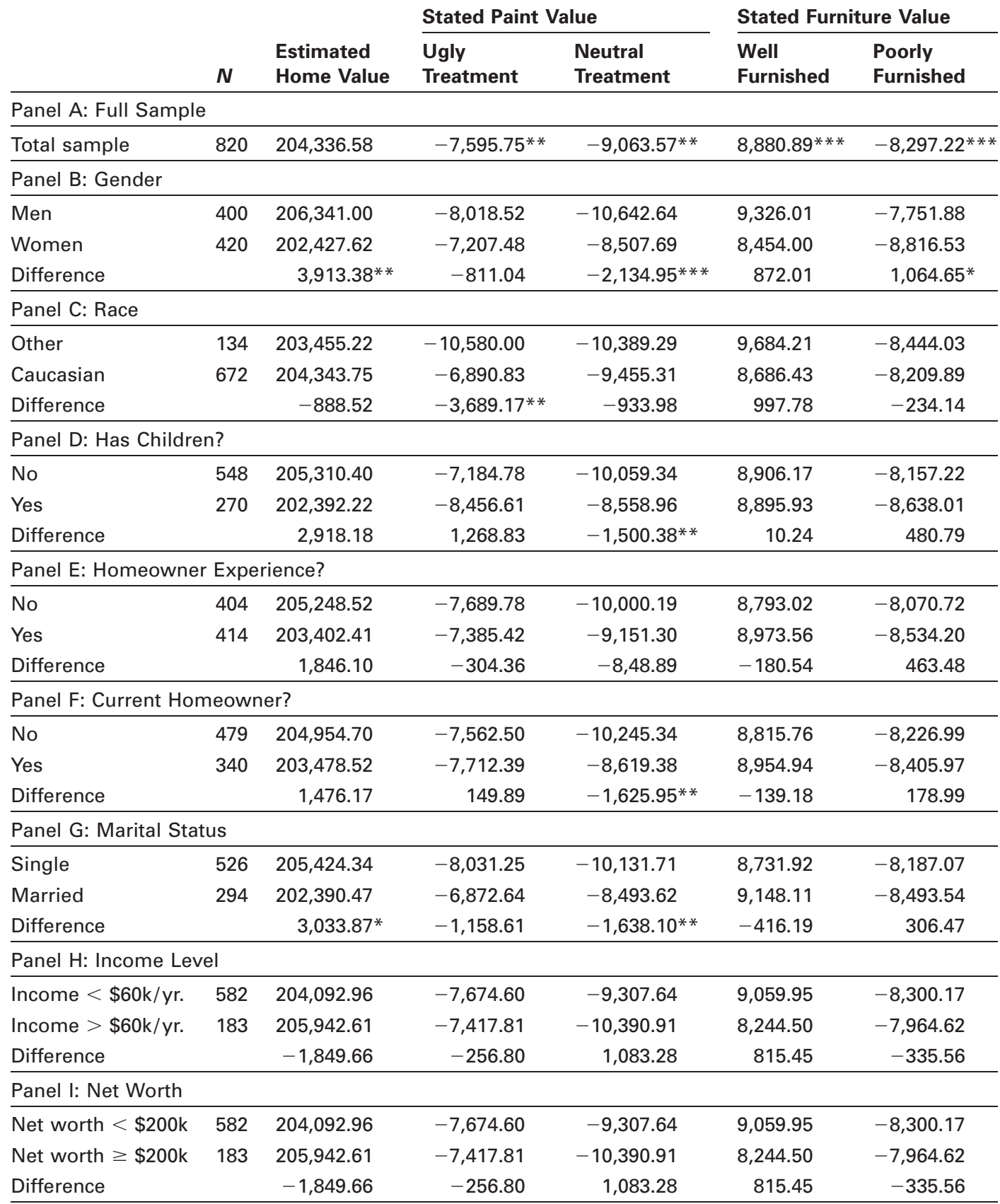

Notes: This table displays mean values and significance levels for the overall sample, as well as for the sample when segmented by demographic characteristics. Significance is indicated between groups within a panel. Significance is based on bootstrapped independent samples t-tests. Bootstrap results are based on 10,000 bootstrap samples. Specific tests were selected after a Levene statistic was computed in order to make the correct assumption regarding homogeneity of variance. In all cases, nonparametric tests were also performed and the results were qualitatively similar.

* Significance at the $10 \%$ level.

** Significance at the $5 \%$ level.

$* * *$ Significance at the $1 \%$ level. 


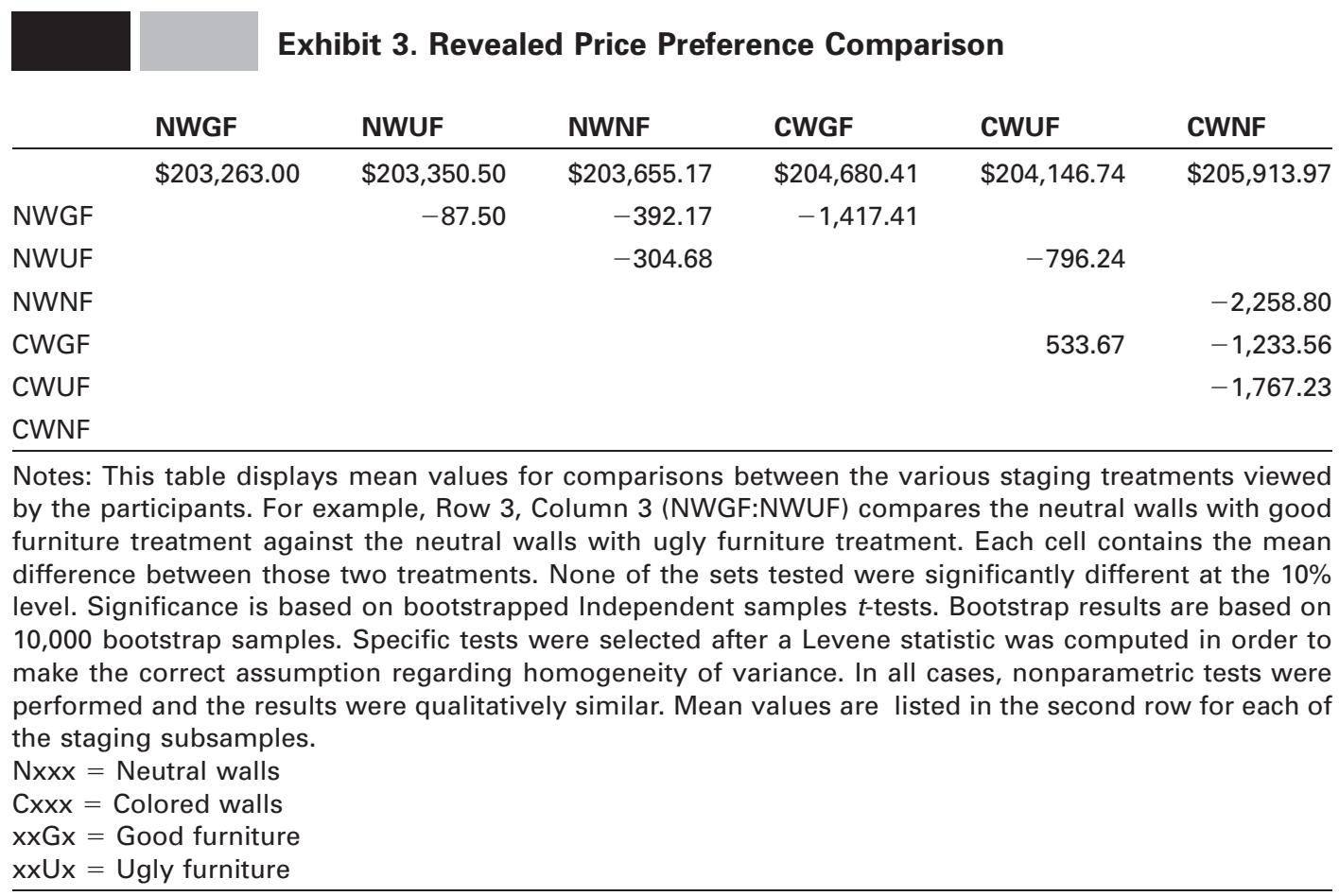

treatment variants using a within subjects design. Because they saw all treatments, it is not possible to determine their revealed opinions of price for each treatment. Instead, we focused on learning their perceptions as to whether or not homebuyers would differentially price the same home based on varying staging conditions. A sample with usable responses from 77 real estate agents was obtained.

\section{Results}

Panel A of Exhibit 2 shows the descriptive univariate statistics for the overall sample of homebuyers who saw the six unique treatments, while Panels B-I segment the results by demographic characteristics. All values in this table reflect the stated opinion of homebuyers' estimate of home values, not their revealed preferences. Alternatively stated, Exhibit 2 reports what homebuyers consciously believe to be the case, not how they actually behave in terms of forming true unconscious opinions of value. The Stated Paint Value columns report what homebuyers who saw the ugly paint color (Ugly Treatments) believe they subtracted due to the unattractive paint versus what those who saw neutral colored walls (Neutral Treatment) believe they would have subtracted had they seen unattractive paint on the walls of the common living area. The difference between the two is significant, indicating that people believe they would penalize poor wall coloring more than they actually did after seeing the walls. ${ }^{13}$

The two Stated Furniture Value columns in Exhibit 2 report the opinion of homebuyers that well (poorly) furnished/staged homes can significantly improve (decrease) the 


\begin{tabular}{|c|c|c|c|c|c|}
\hline \multirow[b]{2}{*}{ NWGF } & \multicolumn{5}{|c|}{$\begin{array}{l}\text { Exhibit 4. Robustness Sample of Real Estate Agent Stated Value } \\
\text { Impacts of Staging Conditions on Home Price }\end{array}$} \\
\hline & NWUF & NWNF & CWGF & CWUF & CWNF \\
\hline$\$ 204,000.00$ & $\$ 198,246.27$ & $\$ 199,427.14$ & $\$ 194,357.14$ & $\$ 190,657.53$ & $\$ 191,673.61$ \\
\hline NWGF & $6,648.44 * * *$ & $5,479.10 * * *$ & $11,539.68^{* * *}$ & & \\
\hline NWUF & & $-1,415.15$ & & $8,179.69 * * *$ & \\
\hline NWNF & & & & & $9,096.97 * *$ \\
\hline CWGF & & & & $3,028.57 * * *$ & $2,278.57^{* *}$ \\
\hline CWUF & & & & & -739.44 \\
\hline \multicolumn{6}{|l|}{ CWNF } \\
\hline \multicolumn{6}{|c|}{$\begin{array}{l}\text { Notes: This table reports the within subject design stated preference results from the robustness data } \\
\text { sample. The robustness data sample was collected from real estate agents concerning how much } \\
\text { homebuyers will differ in their willingness to pay for a home under various staging conditions. Significance } \\
\text { is based on bootstrapped paired samples } t \text {-tests. Bootstrap results are based on 10,000 bootstrap samples } \\
\text { Mean values are listed in the second row for each of the staging subsamples. } \\
\text { Nxxx }=\text { Neutral walls } \\
\text { Cxxx }=\text { Colored walls } \\
x x G x=\text { Good furniture } \\
x x U x=\text { Ugly furniture } \\
\text { * Significance at the } 10 \% \text { level. } \\
\text { ** Significance at the } 5 \% \text { level. } \\
\text { ** Significance at the } 1 \% \text { level. }\end{array}$} \\
\hline
\end{tabular}

opinion of home value even though homebuyers do not get to keep the furniture. ${ }^{14}$ Ignoring the opposing directional effects and just examining the magnitude of the differences, we see the absolute value differences are not significantly different. This reflects a general symmetry in the belief that sellers of well-staged homes will be rewarded, while sellers of poorly staged homes will be penalized. In reference to both stated paint value treatments and furniture treatments, demographics appear to have little to do with explaining differential results.

The results in Exhibit 2 show that people believe proper staging conditions (neutral wall colors and good furnishings) allow sellers to achieve significantly higher home prices, while Exhibit 3 shifts from examining these stated values to understanding true underlying, or revealed values. That is, homebuyers might believe on a conscious level that well-staged homes will sell for more, but do they act according to their stated, or conscious, beliefs? The matrix in Exhibit 3 compares the treatments each time isolating a controlled variable. For example, $-\$ 87.50$ represents the average difference in (revealed) home price estimation between treatments that only differed by good furniture versus bad furniture. ${ }^{15}$ Since participants only took a single tour (a between subjects design where they are unaware of the other treatments and thus not consciously able to override their subconscious belief system), these results much better reflect their true opinions of value inclusive of each intervening variable (treatment). Since none of the treatment differences are statistically significant, the conclusion to be drawn is that while people may think staging conditions (paint color and furniture quality) matter, the reality is that homebuyers form their opinion of value independent of these conditions. Because 
Exhibit 5. Regression Results by Sample Participants

\begin{tabular}{lccc} 
& Estimated Home Value & Overall Impression & Livability \\
\hline Intercept & $205,474.43^{* * *}$ & $7.569^{* * *}$ & $7.260^{* * *}$ \\
\hline Panel A: Key Treatment Variables & & & \\
\hline Ugly paint dummy & $1,705.21$ & $-0.249^{* *}$ & -0.091 \\
Well Staged dummy & -452.53 & 0.067 & 0.301 \\
Not Staged dummy & $-1,079.38$ & $-0.303^{* *}$ & $-0.498^{* *}$ \\
\hline Panel B: Demographic Variables & & & \\
\hline Female dummy & $-3,247.73^{*}$ & -0.045 & $-0.314^{*}$ \\
Has children dummy & $-1,963.50$ & $0.363^{* * *}$ & $0.563^{* * *}$ \\
Married dummy & $-1,415.89$ & 0.150 & 0.119 \\
Caucasian dummy & $1,270.38$ & -0.132 & -0.234 \\
Homeowner experience dummy & $1,175.18$ & 0.121 & 0.077 \\
Annual Income & 448.07 & $-0.140^{* * *}$ & $-0.136^{*}$ \\
Total Net Worth & -480.59 & $-0.086^{* *}$ & -0.081 \\
F-Statistic & 0.658 & 4.105 & 3.161 \\
$P$-value & 0.764 & 0.000 & 0.001 \\
\hline
\end{tabular}

Notes: This table reports the regression results from 3 separate regressions. The dependent variables are the estimated value of the home (the revealed value), the overall impression of the home (1 to 9), and the degree to which the participant could see himself living in the home (1 to 9).

* Significance at the $10 \%$ level.

** Significance at the $5 \%$ level.

$* * *$ Significance at the $1 \%$ level.

homebuyers do not get to keep the furniture and because paint is relatively inexpensive, this failure to allow externalities to impact opinions of home values appears rational.

As a robustness check, we asked 77 real estate agents who convened for our annual market review and research seminar to also take part in a variation of the previously described experiment. ${ }^{16}$ Instead of conducting a between subjects design where both stated and revealed preferences were collected, we used a within subjects design and simply asked the agents to state whether or not they believe staging conditions would impact homebuyers' revealed preferences. The results in Exhibit 4 reveal real estate agents significantly (in 9 of 11 comparisons) hold the belief that homebuyers will be swayed by staging conditions. The magnitude of beliefs is in the same general range as the stated value beliefs of homebuyers. Yet, as already discussed, these stated values are not empirically supported by revealed preference measures. Hence, both agents and homebuyers are incorrect in their understanding of the impact of staging conditions on home price value opinion formation.

Because a controlled experiment holds all else constant directly through the design, empirical results are seldom subjected to further regression analysis. ${ }^{17}$ Still, Exhibit 5 reports the results from three separate regressions where the dependent variables are revealed home price opinion, overall impression of the home (measured on a 9-point interval scale), and the homes' livability rating (measured on a 9-point interval scale). Consistent with the univariate results, when explaining revealed opinion of home price, 
none of the staging conditions are statistically significant. Interestingly, when examining the overall impression of the home, an ugly paint color does significantly detract from the impression as does an empty home. Empty homes also significantly negatively impact the perceived livability. In sum, staging conditions do impact homebuyers' impressions of the home, but these impactions do not directly translate into a lower willingness to pay.

\section{Conclusion}

In this study, we examine the impact of staging conditions (wall coloring in the main living area of the home and furniture selection) in a residential real estate setting. We find that furniture quality and color choices do not appear to have a significant effect on the actual revealed market value of the property, but they do have a strong impact on the perceived livability and overall impression of the home. Given that furnishings do not come with the purchase of the property and that paint is relatively inexpensive, we view this revealed preference measure as a rational position taken by homebuyers.

These results stand in stark contrast to the conscious (stated) opinion of both buyers and real estate agents that staging conditions significantly impact willingness to pay for a home. As such, the findings are new and useful to a large group of stakeholders (sellers and agents). Of course, the goal of sellers is to dispose of their property at the highest possible price in the shortest period of time. As such, we are quick to disclose that, while our experimental design was able to address the issue of price opinion (where transaction data is unsuccessful), we are not able to examine the impact of staging conditions on time on the market. Thus, we are careful not to make definitive statements about the complete effectiveness of staging conditions on the overall selling process.

\section{Appendix}

\section{Selected Experimental Questions asked AFTER the Tour}

Please enter the code just spoken to you

What is your overall impression of this house?

Not at all

Extremely

Favorable

1

2

3

Neutral

5

6

7

8

Favorable

Can you see yourself/family living in this home?

No,

Not at all

1

2

Neutral

Please select the number " 8 " to answer this question.

1

$2 \quad 3 \quad 4$

5

6

7

8
Yes, Absolutely 9

(only for houses that are staged) 
How much do you like the furniture in this home?

Do not like

it at all

1

23

Neutral

$\begin{array}{llll}5 & 6 & 7 & 8\end{array}$

Absolutely

love it

9

(only for ugly paint colors)

How much lower did you adjust the price of this home based on the paint color? $\$$

(only for neutral colored paint)

If this home had an unacceptably ugly paint color on the walls throughout most of the house, how much would you have deducted from your estimate of the home's price? $\$$

When you buy a home, you do not get to keep the furniture/decorations that are inside. But do you think furniture/decorations can influence a buyer's opinion of the price of the home anyway?

A Well Furnished Home

A Poorly Furnished Home

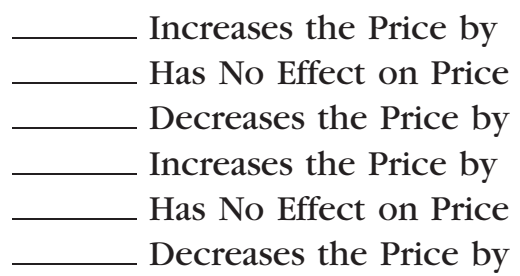

$\$$

$\$$

$\$$

Please select the number " 3 " to answer this question.
1
$2 \quad 3 \quad 4$
5
6
7
8
9

Please share the following information about yourself:

How many homes have you purchased in your lifetime? homes

Gender: Male Female

What is your Age?

Current Marital Status: Single Married

Ethnicity:
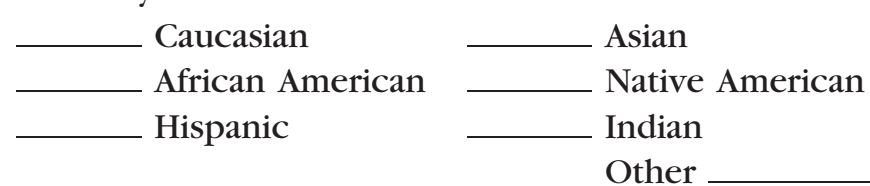

Your Annual Income Level

(Please check the appropriate box)

Under \$20,000

$\$ 20,001-\$ 40,000$

$\$ 40,001-\$ 60,000$

$\$ 60,001-\$ 80,000$

$\$ 80,001-\$ 100,000$

\$100,001 - \$120,000

Over \$120,000 
What is your total net worth? Net worth is defined as total assets (stocks, bonds, price of your home, retirement accounts, etc.) minus total liabilities (outstanding mortgage balance, credit card debt, student loans, auto loans, etc.)

$$
\begin{aligned}
& \text { Less than }-\$ 400,000 \\
& -\$ 400,000 \text { to }-\$ 200,001 \\
& -\$ 200,000 \text { to } \$ 0 \\
& \$ 1 \text { to } \$ 200,000 \\
& \$ 200,001 \text { to } \$ 400,000 \\
& \$ 400,001 \text { to } \$ 600,000 \\
& \$ 600,001 \text { to } \$ 800,000 \\
& \$ 800,001 \text { to } \$ 1,000,000 \\
& \text { Over } \$ 1,000,000
\end{aligned}
$$

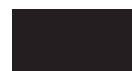

\section{Endnotes}

1 Agents often further advise sellers to de-personalize their home by removing all family photos. All these efforts are geared towards allowing the potential buyer to better visualize themselves in the home.

${ }^{2}$ http://www.homestageddesigns.com/.

${ }^{3}$ It is important to remember that the purpose of MLS data is to aid in the transactions of residential real estate, not to delineate pure measurements of specific variables that lend themselves to the empirical investigations of outside researchers. As a result, researchers who use transaction-based datasets are at the mercy of the data that are deemed worthy of collection and storage by third-party venders whose goals and variable definitions do not necessarily match our own.

${ }^{4}$ In the case of renters, state laws mandate a (differentially) minimum notice be given to tenants.

${ }^{5}$ Conversely, a vacant property can also be easier to show on short notice since there are no occupants who require prior notice. Being easier to show means greater exposure of the property and thus a greater probability of a higher offer being made.

${ }^{6}$ Haurin (1988) suggests that houses with unusual features will remain on the market for a longer period of time. Thus, it may be the case that poor staging or exceedingly unusual colors may contribute to an increased time on the market. Moreover, Rosenthal (2011) recognizes in his pricing model for residential real estate that incurring costs for staging may be a rational choice after the property has been on the market for some time.

7 To ensure our furnishing are as we classify them (good vs. bad), we collected data from participants on the ratings of the home's furnishings (for the trials that have furniture). The difference between treatments is statistically significant at the $99 \%$ level, indicating we were successful in our design.

8 We again asked participants to rate the degree to which they liked the home's paint color and their results were significantly different between the two treatments at the $99 \%$ level, confirming the intention of our design to impose differentially attractive wall colorings in the main living area.

9 If a buyer wants to keep the staged furniture, a separate contract would have to be written and a price agreed upon.

${ }^{10}$ For example, it is possible that the marital status has changed or that the number of children has increased. However, it is unlikely that the person's gender has changed and not possible that their age has decreased. 
11 We run several additional filters on the data to ensure the robustness of the results. For example, we filter people who sped through the experiment too quickly.

${ }^{12}$ We avoid sample selection bias in our robustness sample by ex ante withholding the announcement that we would be collecting data during the meeting.

13 This, of course, could be due strictly to the possibility that they envision a wall coloring even worse than the one used in our study.

${ }^{14}$ Note that we specifically told the participant the furnishings/decorations do not come with the house to be absolutely sure we focused solely on unwarranted value impaction.

15 The effect of wall coloring was controlled for as all homebuyers saw tours with neutral colored walls.

${ }^{16}$ It is important to note that the real estate agents were gathering for a purpose other than to partake in the experiment as this mitigates the potential presence of sample selection bias.

${ }^{17}$ When examining traditionally collected transactions data, it is understood that countless extraneous influences are affecting prices simultaneously. In an attempt to control for this, social sciences typically include all measureable and influential variables as independent control variables in a regression analysis to account for these outside factors. Specifying too many or too few or measuring these variables with error all work towards a lesser ability to understand the true underlying relationships. Alternatively, experimental design controls for all these extraneous influences by not including them in the controlled environmental setting. The concern then shifts to whether or not the results found in the lab will hold in the real world. In this sense, the two available approaches should be recognized for their respective strengths and weaknesses and as being more appropriate in a specific setting, rather than as one being better than the other.

\section{References}

Asabere, P. and F. Huffman. The Impact of Settlement Period on Sales Price. Journal of Real Estate Finance and Economics, 1993, 7:3, 213-19.

Forgey, F., R. Rutherford, and T. Springer. Search and Liquidity in Single-Family Housing. Real Estate Economics, 1996, 24:3, 273-92.

Haurin, D. The Duration of Marketing Time of Residential Housing. Real Estate Economics, 1988, 16:4, 396-410.

Knight, J. Listing Price, Time on Market, and Ultimate Selling Price: Causes and Effects of Listing Price Changes. Real Estate Economics, 2002, 30:2, 213-37.

Rosenthal, E. A Pricing Model for Residential Homes with Poisson Arrivals and a Sales Deadline. Journal of Real Estate Finance and Economics, 2011, 42:2, 143-61.

Seiler, M. The Effect of Perceived Lender Characteristics and Market Conditions on Strategic Mortgage Defaults. Journal of Real Estate Finance and Economics, 2014, 48:2, 256-70.

Seiler, M., M. Lane, and D. Harrison. Mimetic Herding Behavior and the Decision to Strategically Default. Journal of Real Estate Finance and Economics, 2014, 49:4, 621-53.

Seiler, M., V. Seiler, M. Lane, and D. Harrison. Fear, Shame, and Guilt: Economic and Behavioral Motivations for Strategic Default. Real Estate Economics, 2012, 40:S1, 199-233.

Sirmans, C., G. Turnbull, and J. Dombrow. Quick House Sales: Seller Mistake or Luck? Journal of Housing Economics, 1995, 4:3, 230-43.

Springer, T. Single-Family Housing Transactions: Seller Motivations, Price, and Marketing Time. Journal of Real Estate Finance and Economics, 1996, 13:3, 237-54. 
Turnbull, G., C.F. Sirmans, and J. Benjamin. Do Corporations Sell Houses for Less? A Test of Housing Market Efficiency. Applied Economics, 1990, 22:10, 1389-98.

Turnbull, G., and V. Zahirovic-Herbert. Why Do Vacant Homes Sell for Less: Holding Costs, Bargaining Power, or Stigma? Real Estate Economics, 2011, 39:1, 19-43.

We would like to thank Joe Miller, President of HBA Architecture E Interior Design and Troy Hines, Designer, for providing us with the 3-D animations of the six different bome tours used in this study. We would also like to thank Maggi Davis of Keller Williams Realty in Virginia who created the voice-over recordings of the virtual home tour.

Mark A. Lane, Old Dominion University, Norfolk, VA 23529 or malane@odu.edu. Michael J. Seiler, The College of William \& Mary, Williamsburg, VA 23187-8795 or Michael.Seiler@mason.wm.edu.

Vicky L. Seiler, Virginia Wesleyan College, Norfolk, VA 23502 or vseiler@vwc.edu. 
Reproduced with permission of the copyright owner. Further reproduction prohibited without permission. 